\title{
OPTIMAL ESTIMATES FOR THE FRACTIONAL HARDY OPERATOR ON VARIABLE EXPONENT LEBESGUE SPACES
}

\author{
Yoshihiro Mizuta, Aleš NeKVinda And Tetsu Shimomura
}

Abstract. Let $A_{\alpha} f(x)=\frac{1}{\mid B(0,|x|)^{\alpha / n}} \int_{B(0,|x|)} f(t) d t$ be the $n$-dimensional fractional Hardy operator, where $0<\alpha \leqslant n$. We prove optimality results for the action of the operator $A_{\alpha}$ on variable exponent Lebesgue spaces $L^{p(\cdot)}$ and weighted variable exponent Lebesgue spaces, as an extension of $[13,14,17]$.

Mathematics subject classification (2010): 47G10.

Keywords and phrases: Fractional Hardy operator, Banach function space, optimal spaces, weighted Lebesgue spaces.

\section{REFERENCES}

[1] C. Bennett And R. Sharpley, Interpolations of operators, Pure and Appl. Math., vol. 129, Academic Press, New York, 1988

[2] C. Capone, D. Cruz-Uribe And A. Fiorenza, The fractional maximal operator on variable $L^{p}$ space, Rev. Mat. Iberoamericana 23, 3 (2007), 743-770.

[3] D. Cruz-Uribe, A. Fiorenza and C. J. Neugebauer, The maximal function on variable $L^{p}$ space, Ann. Acad. Sci. Fenn. Math. 28, 29, (2003, 2004), 223-238, 247-249.

[4] D. E. Edmunds AND A. NeKVINDA, Averaging operators on $l^{\left\{p_{n}\right\}}$ and $L^{p(x)}$, Math. Inequal. Appl. 5 (2) (2002), 235-246.

[5] A. Gogatishvili, B. OpIC AND L. PICK, Weighted inequalities for Hardy-type operators involving suprema, Collect. Math. 57, 3 (2006), 227-255.

[6] A. Gogatishvili And V. D. Stepanov, Reduction theorems for weighted integral inequalities on the cone of monotone functions (Russian), Uspekhi Mat. Nauk 68 (2013 no. 4 (412)), 3-68.

[7] K.-G. Grosse-ERDMANN, The blocking technique, weighted mean operators and Hardy's inequality, Lect. Notes Math. 1679, Springer, Berlin etc., 1998.

[8] J. Heinonen, T. KilPEläINEN AND O. MARTio, Nonlinear potential theory of degenerate elliptic equations, Clarendon Press, 1993.

[9] O. KovÁčIK AND J. RÁKosníK, On spaces $L^{p(x)}$ and $W^{k, p(x)}$, Czechoslovak Math. J., Praha 41 (1991), 592-618.

[10] A. Kufner And L. E. Persson, Weighted inequalities of Hardy type, World Scientific Publishing Co., Inc., River Edge, NJ, 2003.

[11] J. LANG AND A. NEKVINDA, A difference between continuous and absolutely continuous norms in Banach function spaces, Czechoslovak Math. J., Praha 47 (1997), 221-232.

[12] J. LANG, A. NEKVINDA AND J. RÁKosNíK, Continuous norms and absolutely continuous norms in Banach function spaces are not the same, Real Anal. Exch. 26(1) (2000/2001), 345-364.

[13] Y. Mizuta, A. NeKVinda AND T. Shimomura, Hardy averaging operator on generalized Banach function spaces and duality, Z. Anal. Anwend. 32 (2013), 233-255.

[14] Y. Mizuta, A. Nekvinda And T. Shimomura, Optimal estimates for the fractional Hardy operator, Studia Math. 227 (2015), 1-19.

[15] Y. Mizuta And T. Shimomura, Weighted Sobolev inequality in Musielak-Orlicz space, J. Math. Anal. Appl. 338 (2012), 86-97.

[16] B. MucKenhoupt, Weighted norm inequalities for the Hardy maximal function, Trans. Amer. Math. Soc. 165 (1972), 207-226. 
[17] A. NEKVINDA AND L. PICK, Optimal estimates for the Hardy averaging operator, Math. Nachr. 283 (2010), 262-271.

[18] A. Nekvinda AND L. Pick, Duals of optimal spaces for the Hardy averaging operator, Z. Anal. Anwend. 30 (2011), 435-456.

[19] E. M. Stein, Singular integrals and differentiability properties of functions, Princeton Univ. Press, Princeton, 1970. 